\title{
Association of Obesity-Mediated Insulin Resistance and Hypothalamic Volumes: Possible Sex Differences
}

\author{
Jenny Ha, ${ }^{1}$ Jessica I. Cohen, ${ }^{1}$ Aziz Tirsi, ${ }^{1}$ and Antonio Convitt ${ }^{1,2,3}$ \\ ${ }^{1}$ Brain, Obesity, and Diabetes Laboratory (BODyLab), Department of Psychiatry, New York University School of Medicine, \\ 145 East 32nd Street, 8th Floor, New York, NY 10016, USA \\ ${ }^{2}$ Department of Medicine, New York University School of Medicine, 145 East 32nd Street, 8th Floor, New York, NY 10016, USA \\ ${ }^{3}$ Nathan Kline Institute for Psychiatric Research, 140 Old Orangeburg Road, Orangeburg, NY 10962, USA
}

Correspondence should be addressed to Antonio Convit; antonio.convit@med.nyu.edu

Received 7 June 2013; Revised 25 July 2013; Accepted 7 August 2013

Academic Editor: Viswanath Devanarayan

Copyright (C) 2013 Jenny Ha et al. This is an open access article distributed under the Creative Commons Attribution License, which permits unrestricted use, distribution, and reproduction in any medium, provided the original work is properly cited.

The hypothalamus is important in hunger and metabolism. Although a lot is known about the basic role of the human hypothalamus, less is known about how the in vivo volume is affected in obesity, particularly among adolescents. Based on pediatric body mass index percentiles, 95 participants were assigned to lean or obese groups. All subjects had medical evaluations, including fasting blood tests, to assess insulin sensitivity and circulating CRP and neurotrophins (NGF and BDNF) and an MRI of the brain. Hypothalamic volumes were measured by a segmentation method combining manual and automated steps. Overall, obese participants had descriptively smaller hypothalamic volumes, although this difference did not reach statistical significance; however, among obese participants, females had significantly smaller hypothalamic volumes than their male counterparts. There was a significant interaction between insulin resistance and sex on hypothalamus volume; obese females with significant insulin resistance have smaller hypothalamic volumes than obese males. Obese adolescents had higher circulating CRP and neurotrophin levels. Furthermore, among obese females, BDNF concentrations were inversely associated with hypothalamus volumes $(r=-0.48)$. Given this negative association between BDNF and hypothalamus volumes among obese insulin-resistant females, elevated neurotrophin levels may suggest an attempt at protective compensation.

\section{Introduction}

The prevalence of obesity is increasing at an alarming rate worldwide. In the United States, this trend is especially alarming in children and adolescents. According to the Centers for Disease Control, in 2008, 18.1\% of adolescents (12-19 years old) were considered obese, which is 3 -fold higher than that in the 1980s [1]. Adolescent obesity is a strong predictor of adulthood obesity as excessive weight gain occurring in adolescence is unlikely to decrease over time [2]. Obesity can lead to many comorbid conditions such as hypertension, atherosclerosis, and type 2 diabetes [3], and weight gain during adolescence may increase the risks for these morbidities in adulthood [4]. Furthermore, obese adolescents with type 2 diabetes, as well as those with metabolic syndrome, show reductions in cognitive performance and white matter microstructural integrity [5]. Reductions in hippocampal volumes and increases in global brain atrophy are also observed in these adolescents with clinical and preclinical metabolic diseases [5-7]. Unlike the hippocampus, little is known about the impact of obesity on the in vivo volume of the hypothalamus. The hypothalamus is a small but complex and multifunctional area of the brain that is involved in autonomic, endocrine, and behavioral functions. It is comprised of several nuclei that serve specific functions such as food intake and metabolic control [8-10]. The working model for hypothalamic regulation of food intake and energy balance is the set-point theory [11], and obesity may be associated with an elevated set point [12], which differs between individuals and may fluctuate throughout one's life [13]. Given the importance of the hypothalamus in the control of nutrient intake and metabolism [14] and since the majority of hypothalamus and obesity studies have been conducted utilizing animal models $[15,16]$, the need for human studies is pressing. 
There is evidence that more female adolescents are diagnosed with type 2 diabetes than male adolescents [17]. It is known that females with type 2 diabetes, despite better glucose control than males with diabetes, have greater hippocampal volume reductions than those observed in males [18]. In addition, females with type 2 diabetes are at greater risk for cardiovascular disease, increased risk of mortality from coronary heart disease, and end-stage renal disease than age- and weight-matched males [19-21]. Furthermore, females are also more likely than their male counterparts to have dyslipidemia [22-24]. Given the strong connection between obesity and hypothalamic inflammation [25-27], as well as the higher rates of inflammation among females $[28,29]$, ascertaining whether obesity impacts hypothalamic volumes and whether females are disproportionately affected is of considerable interest and could be a significant contribution to the field.

Obesity is considered a chronic inflammatory condition [30]. Neurotrophins, such as brain-derived neurotrophic factor (BDNF) and nerve growth factor (NGF), protect neurons from inflammatory events [31]. The hypothalamus and hippocampus contain the highest levels of BDNF expression [32]. BDNF gene expression, which is mediated by NGF, increases in response to inflammation and is involved in many conditions, such as inflammatory bowel disease $[33,34]$ and age-associated myocardial injury [35]. Previous studies show conflicting data regarding BDNF expression in obese adolescent populations, with some studies reporting BDNF reductions in obese subjects [36] and others reporting elevations [37]. Although a previous report demonstrated that late pubescent boys have greater BDNF levels than late pubescent girls, this was based on a small sample size. In contrast, adult women have been reported to have higher BDNF levels than men [38]. A previous study reported elevated serum BDNF levels in female adults with type 2 diabetes compared to healthy female controls [39]. In addition, elevations in NGF have been associated with obesity and metabolic syndrome in women [40]. Furthermore, our group has reported that although adult women with obesityassociated impaired insulin function have lower BDNF levels overall, those with poorer memory performance had higher BDNF levels, perhaps as a compensatory mechanism [41]. A recent study [42] illustrated differences in the inflammatory profile seen in obese adolescents compared to what is seen in obese adults, although acute-phase reactants, such as Creactive protein (CRP) and fibrinogen, were elevated in obese adolescents compared to lean controls, consistent with adult literature [43-46]; no such differences were seen in proor anti-inflammatory cytokines. For these reasons, we were interested in ascertaining whether there may be differences in neurotrophins, even though differences in cytokines were not observed.

We hypothesized that although increased BMI and waist circumference (and their associated increases in inflammatory cytokines) were associated with smaller adult hypothalamic volumes, given the lack of clear elevations in inflammatory cytokines in obese adolescents, obese adolescents' hypothalamic volumes will be indistinguishable from those of healthy weight adolescents. Further, we also proposed that compensatory mechanisms, such as possible increases in peripheral neurotrophin concentrations, which have been shown to reflect central BDNF levels [47], may protect the hypothalamus from injury and contribute to the hypothesized absence of hypothalamic volume reductions among obese adolescents. However, given the sex-specific increases in inflammation and the greater vulnerability of the female brain to metabolic-related damage, we further hypothesized that the associations between excess weight and hypothalamic volumes may differ by sex among adolescents. To test these hypotheses, we performed MRI-based hypothalamic and third ventricle volume measurements by utilizing a modification of other published methods [48-52] and ascertained whether group or sex differences were influenced by differences in inflammatory markers and neurotrophins.

\section{Methods}

2.1. Participants. Thirty-two lean and 63 obese adolescents, well-matched on age (calculated by subtracting the participants' self-reported birth date from the date of their first visit to our laboratory), sex, ethnicity (self-reported according to NIH standards; please see http://grants.nih.gov/grants/funding/women_min/race_ethnicity_qa.htm\#1027), and socioeconomic status [53], were included in the study (Table 1). The subjects were consecutive cases evaluated as part of an NIH-sponsored study approved by the New York University School of Medicine Institutional Review Board. All of the participants (and if they were under 18 years of age, one of their parents) signed informed consent and received compensation for their time and inconvenience. Potential participants were screened to rule out exclusionary preexisting medical (hypertension, dyslipidemia, polycystic ovary disease, or insulin resistance were permitted) and psychiatric conditions. Additionally, potential subjects were excluded if they had a history of significant head trauma, hydrocephalus, mental retardation, or neurological disorders. Because we excluded individuals with a history of neurological and psychiatric diseases prior to entering the study, we did not encounter any brain abnormalities that were exclusionary. Potential participants were also excluded if they were on medication other than cholesterol, diabetes, hypertension, and/or asthma. Namely, psychoactive medications and corticosteroids were excluded. Among the type 2 diabetic participants, medications included netformin, Novolog, and Glucophage. Participants' height (Seca 220, Germany) and weight (Seca 700, Germany) were measured during a physical examination. Those who were 18 years and older with a body mass index $(\mathrm{BMI}) \leq 24.9 \mathrm{~kg} / \mathrm{m}^{2}$ were considered lean, and participants with a BMI $\geq 30 \mathrm{~kg} / \mathrm{m}^{2}$ were included in the obese group. Participants who were younger than 18 and had a BMI-for-age $<85$ th percentile and $\geq 95$ th percentile were considered lean and obese, respectively. None of the participants were on medications (i.e., anti-inflammatory drugs, beta agonists) that could confound our results. Participants with a CRP $>10 \mathrm{mg} / \mathrm{L}$ were excluded from CRP analyses, because we could not exclude that they were due to a minor infection (such as acne) and not reflective of chronic lowgrade proinflammatory state. 
TABLE 1: Group demographics.

\begin{tabular}{|c|c|c|c|}
\hline & $\begin{array}{c}\text { Lean } \\
(n=32) \\
\end{array}$ & $\begin{array}{c}\text { Obese } \\
(n=63) \\
\end{array}$ & $P$-value \\
\hline Age (years) & $\begin{array}{l}17.3 \pm 1.6 \\
(14.3-20.1)\end{array}$ & $\begin{array}{l}17.5 \pm 1.8 \\
(14.3-21.6)\end{array}$ & .79 \\
\hline Sex (\% female) & 59.2 & 61.9 & .81 \\
\hline Grade & $\begin{array}{l}11.8 \pm 1.9 \\
(9.0-16.0)\end{array}$ & $\begin{array}{r}11.6 \pm 1.7 \\
(8.1-16.1)\end{array}$ & .57 \\
\hline Socioeconomic status & $2.6 \pm 1.4$ & $2.1 \pm 1.2$ & .19 \\
\hline $\operatorname{BMI}\left(\mathrm{kg} / \mathrm{m}^{2}\right)$ & $\begin{array}{c}21.1 \pm 2 \\
(17.44-24.9)\end{array}$ & $\begin{array}{l}37.7 \pm 5.9 \\
(27.8-49.8)\end{array}$ & $<.001$ \\
\hline BMI percentile & $\begin{array}{c}50.9 \pm 22.5 \\
(9.0-79.9)\end{array}$ & $\begin{array}{c}98.2 \pm 1.3 \\
(95.2-99.9)\end{array}$ & $<.001$ \\
\hline Waist circumference $(\mathrm{cm})$ & $\begin{array}{c}75.3 \pm 6.2 \\
(66.0-88.0)\end{array}$ & $\begin{array}{c}112.9 \pm 13.4 \\
(88.0-147.0)\end{array}$ & $<.001$ \\
\hline Waist:height & $\begin{array}{l}0.4 \pm 0.0 \\
(0.39-0.5)\end{array}$ & $\begin{array}{c}0.7 \pm 0.1 \\
(0.51-0.82)\end{array}$ & $<.001$ \\
\hline Glucose (mg/dL) & $\begin{array}{l}74.6 \pm 6.9 \\
(62.0-89.0)\end{array}$ & $\begin{array}{c}97.4 \pm 55.2 \\
(62.0-343.0)\end{array}$ & .004 \\
\hline Insulin (IU/mL) & $\begin{array}{l}7.1 \pm 3.3 \\
(2.0-15.2)\end{array}$ & $\begin{array}{l}22.8 \pm 19.2 \\
(2.2-123.0)\end{array}$ & $<.001$ \\
\hline HOMA-IR & $\begin{array}{l}1.3 \pm 0.6 \\
(0.36-2.5)\end{array}$ & $\begin{array}{c}5.5 \pm 5.5 \\
(0.52-33.4)\end{array}$ & $<.001$ \\
\hline Hemoglobin A1C (\%) & $\begin{array}{l}5.2 \pm 0.4 \\
(4.6-6.8)\end{array}$ & $\begin{array}{l}6.2 \pm 2.1 \\
(4.7-14.6)\end{array}$ & .001 \\
\hline Triglycerides & $\begin{array}{l}67.7 \pm 45.9 \\
(25.0-165.0)\end{array}$ & $\begin{array}{c}93.9 \pm 45.9 \\
(24.0-228.0)\end{array}$ & .002 \\
\hline Total cholesterol (mg/dL) & $\begin{array}{l}157.3 \pm 29.9 \\
(100.0-212.0)\end{array}$ & $\begin{array}{l}166.2 \pm 30.3 \\
(113.0-263.0)\end{array}$ & .18 \\
\hline HDL (mg/dL) & $\begin{array}{l}55.4 \pm 11.3 \\
(35.0-80.0)\end{array}$ & $\begin{array}{c}42.3 \pm 9.4 \\
(26.0-66.0)\end{array}$ & $<.001$ \\
\hline $\mathrm{LDL}(\mathrm{mg} / \mathrm{dL})$ & $\begin{array}{l}88.5 \pm 24.9 \\
(45.0-139.0)\end{array}$ & $\begin{array}{l}103.4 \pm 25.7 \\
(59.0-164.0)\end{array}$ & .01 \\
\hline CRP (mg/L) & $\begin{array}{c}0.8 \pm 1.7 \\
(0.05-9.30)\end{array}$ & $\begin{array}{c}3.2 \pm 2.4 \\
(0.3-9.90)\end{array}$ & $<.001$ \\
\hline Fibrinogen (mg/dL) & $\begin{array}{c}285.8 \pm 42.0 \\
(220.0-376.0)\end{array}$ & $\begin{array}{c}349.8 \pm 77.7 \\
(189.0-565.0)\end{array}$ & $<.001$ \\
\hline Systolic BP (mmHg) & $\begin{array}{c}100.2 \pm 8.1 \\
(88-118)\end{array}$ & $\begin{array}{c}116.0 \pm 13.1 \\
(96-160)\end{array}$ & $<.001$ \\
\hline Diastolic BP (mmHg) & $\begin{array}{c}61.8 \pm 5.6 \\
(50-80)\end{array}$ & $\begin{array}{c}68.1 \pm 9.0 \\
(52-100)\end{array}$ & $<.001$ \\
\hline
\end{tabular}

Data are presented as mean $\pm \mathrm{SD}(\min -\max )$.

2.2. Classification of Participants into Those with and without Insulin Resistance. By definition, adolescents with a diagnosis of type 2 diabetes mellitus have marked insulin resistance. Also, because adolescents with type 2 diabetes can in most cases still mount a strong insulin response, they have a high degree of fasting insulinemia. Adolescents without type 2 diabetes were considered insulin resistant if they had a homeostasis model assessment of insulin resistance (HOMAIR) score, an estimate of insulin resistance determined from fasting insulin and glucose values, $\geq 3.99$ [54-56]. For all fasting blood draws, participants were instructed not to consume any food or beverage, with the exception of water, after 10:00 pm. the night prior to blood collection. This resulted in 10-12 hours of fasting. Furthermore, given that in our experience obese adolescents with type 2 diabetes and those with marked insulin resistance and metabolic syndrome have very similar brain structural abnormalities $[5,7]$, we placed obese adolescents with type 2 diabetes and those with marked insulin resistance into one group for some analyses.

2.3. Blood Collection. Following 10-12 hours of fasting, blood was collected from all participants at 09:00 am in a standardized fashion. Standard blood tests, such as cellular blood count with differential, comprehensive metabolic profile including glucose and insulin levels, lipid profile, hemoglobin A1C, CRP, and fibrinogen levels, were performed at the NYU Medical Center Clinical Laboratories. The highsensitivity (cardio) CRP level was measured using an enzymatic immunoassay slide (VITROS CRP, Ortho Clinical Diagnostics). Using blood samples collected in fluorinated tubes, the fasting blood glucose level was measured using a glucose oxidase method (VITROS 950 AT, Johnson \& Johnson), and insulin was assayed using chemiluminescence (Advia Centaur, Bayer corporation). Total cholesterol, high density lipoprotein (HDL-C), low-density lipoprotein (LDLC), and triglycerides levels were analyzed using chemistry slides (VITROS DT, Johnson \& Johnson). The glycatedhemoglobin level was measured using an automated method (HPLC, Tosoh Corporation) certified by the National Glycohemoglobin Standardization Program. In addition to the blood samples used for the clinical labs, samples were collected in EDTA tubes, placed immediately on ice, and spun at $4^{\circ} \mathrm{C}$ at 2,300 RPM for 10 minutes, and the plasma was stored at $-80^{\circ} \mathrm{C}$ for neurotrophin assays (see below), which were performed at the NYU Clinical Translational Science Institute core laboratory.

2.4. Circulating Neurotrophin Measurements. Plasma samples previously stored at $-80^{\circ} \mathrm{C}$ were thawed on ice. Enzymelinked immunosorbent assays (ELISA) using multiplex plates (Millipore, Billerica, MA, USA) were performed on a subset of the population (18 lean and 31 obese). The plates arrived from the manufacturer precoated with antibodies to the proteins of interest. Plasma samples were loaded onto the plates per the manufacturer's instructions $(50 \mu \mathrm{L}$ of plasma was used) and read on a Luminex plate reader (Austin, TX, USA) which detects fluorescent intensity. Protein concentration was determined by comparing the unknown sample concentrations to those of a standard curve. The coefficients of variance were between 7.2 and $9.4 \%$.

\subsection{Magnetic Resonance Imaging}

2.5.1. Brain MRI Acquisition. All participants were scanned on the same 1.5T Siemens Avanto MRI system (Siemens Healthcare, Malvern, PA, USA) utilizing identical sequence parameters. For the volume measurements, a T1-weighted magnetization-prepared rapid acquisition gradient echo (MPRAGE) sequence was acquired in the coronal pathological angle (TR $1300 \mathrm{~ms}$; TE $4.38 \mathrm{~ms}$; T1 $800 \mathrm{~ms}$; FOV $250 \times 250$; 196 slices; slice thickness $1.2 \mathrm{~mm}$; NEX 1; flip 


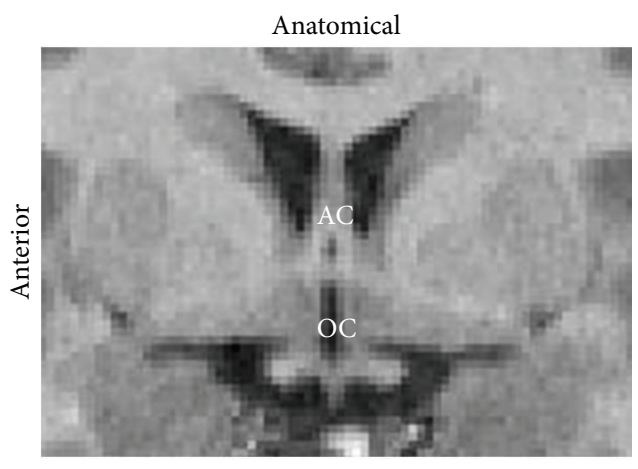

(a)

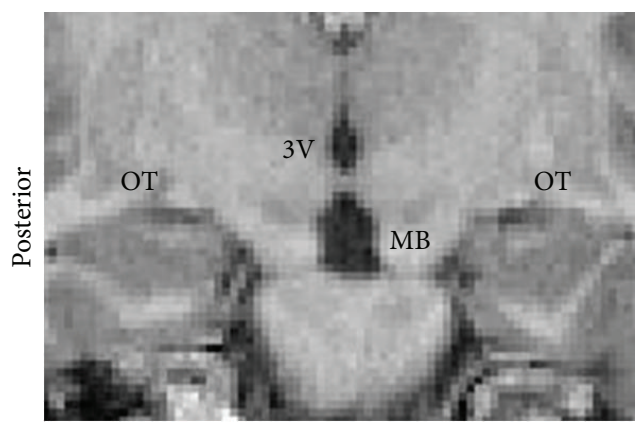

(c)

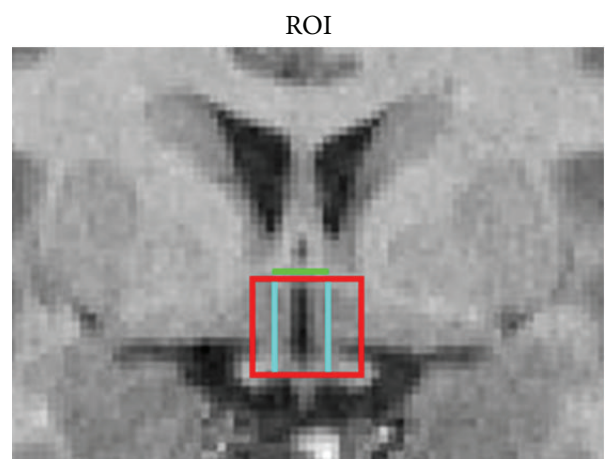

(b)

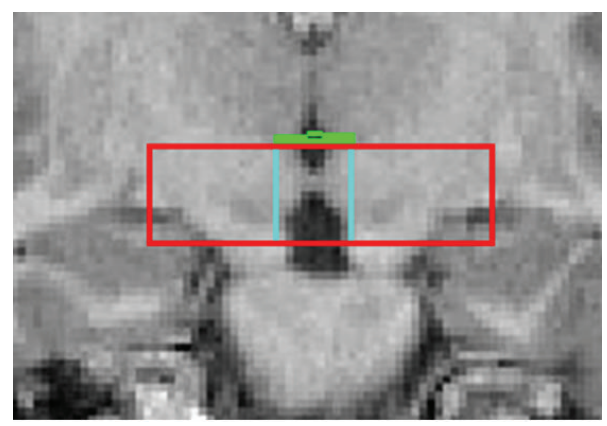

(d)

FIgURE 1: Anatomical landmarks for the determination of the hypothalamus and third ventricle (3V) regions of interest (ROIs). (a) Anteriormost coronal view showing the anterior commissure (AC) and optic chiasm (OC). (b) Hypothalamus (red), third ventricle (3V, blue), and anterior commissure and posterior commissure (AC-PC) plane (green) ROIs on the anteriormost coronal slice of the hypothalamus region. (c) Posteriormost coronal view showing the 3V, mammillary bodies (MB), and optic tracts (OT). (d) Hypothalamus, 3V, and AC-PC plane ROIs on the posteriormost coronal slice of the hypothalamus region.

angle $15^{\circ}$ ). To rule out white matter diseases and to ensure that subjects met the inclusion and exclusion criteria, fast fluid-attenuated inversion recovery (FLAIR; TR $9000 \mathrm{~ms}$; TE $97 \mathrm{~ms}$; FOV $210 \times 201$; 1 average and 2 concatenations; flip angle $145^{\circ}$ ) images were used. Subjects with evidence of infarcts, hemorrhages, intracranial masses, hydrocephalus, or significant white matter lesions were excluded from the study.

The MPRAGE images were intensity normalized and then used to define operator-based regions of interest (ROIs) for the volumetric analyses. All ROIs were drawn blind to participants' identity, endocrine data, and group membership. Reformatted sagittal images were created, and the dural and cerebellar tentorium margins were outlined across multiple slices to estimate intracranial vault (ICV) size, which was then used to correct for head-size variations across participants. For more details, refer to Gold et al. [57].

\subsubsection{Volumetric Hypothalamus Measurements and Deter-} mination of Boundaries. By building on several established methods [48-52], we utilized an in-house manual drawing program (MIDAS.1.11) to create the ROI for the hypothalamus on coronal slices. We defined the anterior boundary of the hypothalamus as the first coronal slice, where the complete anterior commissure (AC) was visualized crossing the interhemispheric space (Figures 1(a), 1(b), and 1(d)). As the majority of hypothalamic nuclei are located anterior to the mammillary bodies, we defined the posterior boundary of the hypothalamus as the coronal slice that included the posteriormost aspect of the mammillary bodies (Figures 1(c) and $1(\mathrm{~d}))$ [58].

The superior boundary of the hypothalamus was defined as the horizontal plane that connects the anterior and the posterior commissures (AC-PC plane). The PC was found approximately $24 \mathrm{~mm}$ (about 20 coronal slices) posterior to the coronal plane, where the AC bisected the interhemispheric plane (the anterior boundary of the hypothalamus). By using a volume of interest function in MIDAS.1.11, the $\mathrm{AC}$ and $\mathrm{PC}$ were connected and the superior boundary plane was visible on all of the coronal planes spanning the AC-PC distance (Figures $1(\mathrm{~b})$ and $1(\mathrm{~d})$ ). The inferior boundary on anterior slices was the center of the optic chiasm (excluding the infundibular stalk) (Figures 1(a) and 1(b)). On posterior sections, the inferior boundary of the hypothalamus region was defined as the ventralmost aspect of the mammillary bodies (Figures 1(c) and 1(d)).

We utilized the optic tracts as a readily identifiable lateral margin level for the hypothalamus (Figures 1(b), 1(c), and 1(d)). The white matter that demarcates the histological lateral boundaries of the hypothalamus is not readily visible on the MRI. By using the optic tracts, which are positioned lateral to this white matter, and coupling the lateral boundary defined by the optic tracts with an automated gray-white segmentation within these boundaries (see below), we were able to increase our interrater reliability. In most cases 


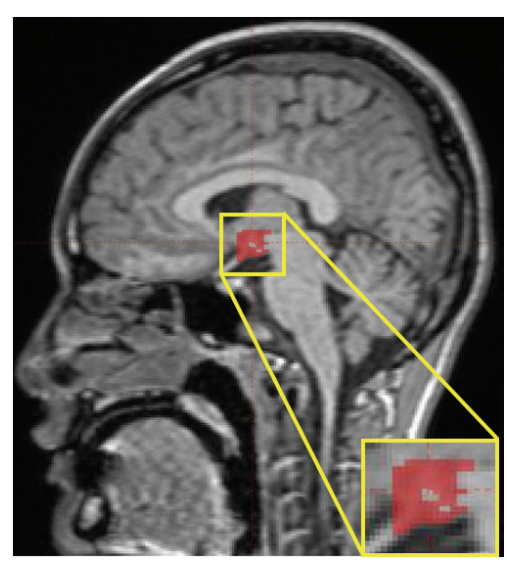

(a)

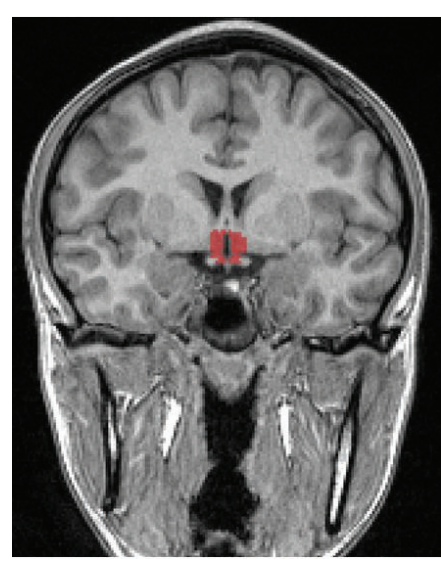

(b)

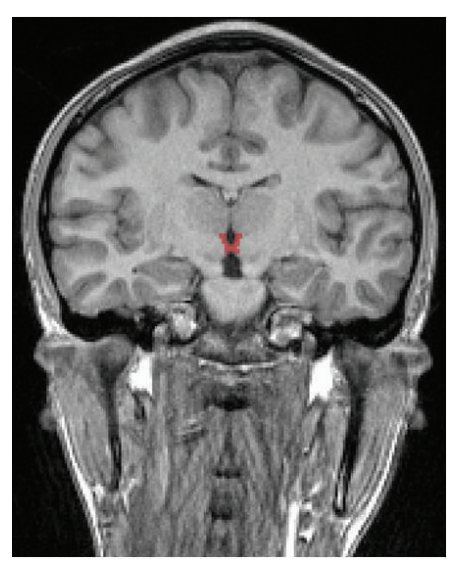

(c)

FIGURE 2: Sagittal and coronal views of the gray matter segment and hypothalamus regions of interest (ROIs) after intersection. (a) Medial sagittal and inset views of the hypothalamus ROI. (b) Anteriormost and (c) posteriormost coronal slices of the hypothalamus ROI. Volume of the hypothalamus was obtained by summing the volume of all the sections, where the hypothalamus between (and including) sections is depicted in (b) and (c).

the hypothalamus, so defined, spanned $96-120 \mathrm{~mm}$ in the anterior-posterior dimension (8-10 coronal sections).

To utilize the volume of the third ventricle as a related (albeit separate) measure of hypothalamic structural integrity, we utilized the same anterior, posterior, superior, and inferior boundaries of the hypothalamus and drew lateral boundaries on the third ventricle that included some gray matter as well as all the easily identified CSF (Figures 1(b) and $1(\mathrm{~d})$ ). A precise lateral boundary was not needed given that a segmentation step, which will be described in detail immediately below, would remove the extraneous gray matter.

The brains were segmented into gray matter and white matter and CSF using Statistical Parametric Mapping 2 (SPM2) software (University College London, London, UK) and Matlab 6.0 (MathWorks, Natick, MA, USA). Our thresholds for gray matter and CSF were set to intensities between $0.50-1.00$ and $0.75-1.10$, respectively. The hypothalamic ROI was intersected with the gray matter segment. Those portions that were not included represented the white matter tracts adjacent to the hypothalamus on each slice (Figure 2). Any gray matter that appeared lateral to these unbiased and automatically determined white matter tracts was manually removed. The third ventricle ROI was intersected with the CSF segment without subsequent manual removal of excess CSF. These procedures generated the hypothalamus and third ventricle volumes.

To estimate the interrater reliability of our method, two investigators independently performed the measurement on 10 randomly selected cases. Interrater reliability was assessed for the middle slice of the hypothalamic region (if the hypothalamus was present on an odd number of slice sections, the middle slice was chosen; if the hypothalamus was present on an even number of slices, the anterior slice of the two possible slices was chosen) as well as for the entire hypothalamic volume. The interclass correlation coefficients (ICC) for the middle slice and total hypothalamus volumes were 0.86 and 0.91 , respectively.
2.6. Statistical Analysis. Data were analyzed using SPSS for Windows version 19.0 (SPSS, Inc., Chicago, IL, USA). The Kolmogorov-Smirnov and Shapiro-Wilk tests were used to test for normality. Independent $t$-tests, with a $95 \%$ confidence interval, were used to investigate group differences in HOMA, total cholesterol, HDL, LDL, fibrinogen, systolic blood pressure, intracranial vault volumes, and residualized hypothalamus and third ventricle volumes. The Mann-Whitney $U$ test, with a nonparametric $95 \%$ confidence interval, was used to investigate group differences in nonnormally distributed variables. A Pearson correlation coefficient was used to assess the relationship between circulating BDNF measurements and hypothalamus volumes (accounting for ICV, residualized) in the obese group. In the linear and hierarchical regressions investigating the interaction between the effects of sex, BMI, and HOMA-IR on hypothalamus volume, sex, ethnicity, and blood pressure were used as potential confounds. To adjust for head-size variability, hypothalamus and third ventricle volumes were adjusted (residualized) to ICV size using analysis of variance.

\section{Results}

3.1. Demographic Data. There were no significant group differences in age, sex, and socioeconomic status. As expected, obese adolescents had significantly higher BMI, waist circumference, and waist-to-height ratios compared to the lean group $(P<.001)$. Additionally, obese adolescents had higher fasting glucose $(P=.004)$, hemoglobin $\mathrm{AlC}$, fasting insulin, CRP, fibrinogen, and HOMA-IR values (all $P<.001$ ). The obese group also had lower HDL, higher LDL and triglycerides concentrations, and higher blood pressure than the lean group (Table 1). None of the adolescents in the lean control group met criteria for significant insulin resistance (type 2 diabetes or HOMA-IR $\geq 3.99$ ), whereas within the obese group, 40 (23 females and 17 males) adolescents (63\%) fulfilled this criterion. Obese insulin-resistant adolescents, in addition to the expected differences in HOMA-IR, fasting 
TABLE 2: Hypothalamus and third ventricle volume.

\begin{tabular}{lccc}
\hline & Lean $(n=29)$ & Obese $(n=62)$ & $P$ value \\
\hline Hypothalamus (cc) & $1.48 \pm 0.12$ & $1.54 \pm 0.22$ & .11 \\
Third ventricle (cc) & $0.24 \pm 0.06$ & $0.23 \pm 0.11$ & .94 \\
Intracranial vault (cc) & $1213.3 \pm 130.7$ & $1192.5 \pm 132.6$ & .25 \\
\hline
\end{tabular}

Data are presented as absolute volumetric mean \pm SD. Comparisons for hypothalamus and third ventricle were performed on intracranial vaultresidualized volumes to yield the results in the table. Four subjects (1 lean female, 2 obese males, and 1 obese female) did not have MRI data.

insulin, fasting glucose, and hemoglobin A1C values from the noninsulin-resistant obese adolescents, also differed on BMI, waist circumference, triglycerides, and systolic blood pressure. LDL, HDL, CRP, and fibrinogen did not differ between these two obese subgroups.

3.2. Neurotrophin Concentrations. The subgroup with available neurotrophin data did not differ from the group that did not have these data in age, sex, or obesity status Circulating concentrations of BDNF were significantly higher in the obese group (mean $\pm \mathrm{SD}$, min-max) $(230.82 \pm 125.3$, 45.9$535.0)$ compared to the lean group $(129.83 \pm 48.7,20.4-210.0)$ $(P<.001)$, whereas NGF was not statistically significant (lean $3.83 \pm 1.78,0.42-7.24$; obese $4.62 \pm 2.3,1.81-11.50)(P=.88)$. No sex differences were found when comparing all males and females or when comparing the lean and obese groups separately.

3.3. Hypothalamus Volumes. The hypothalamic volumes obtained were in keeping with those expected from histological studies [59]. See Table 2 for the group mean volumes. Please note that Table 2 describes the absolute volume measurements. There was a significant correlation between hypothalamus and ICV volumes $(r=.36, P=.001$ for all participants; $r=.44, P<.001$ for obese participants), therefore, volumetric analyses were performed utilizing ICV-adjusted (residualized) hypothalamus volumes. Overall, obese participants had descriptively smaller hypothalamic volumes, although they did not differ statistically $(F=3.82, P=.107$, and $\mathrm{df}=89$ ). Similarly, there were no overall weight group differences in the middle hypothalamus slice volume. The volume of the third ventricle and ICV also did not differ between groups (Table 2). Given the reported sex-associated differences in inflammation as well as the higher rate of medical and brain complications from metabolic disease among women, despite the lack of overall hypothalamus obesity group difference, we explored whether there were sex differences in hypothalamus volume separately for each of the two BMI groups. We found that relative to obese males, obese females had smaller hypothalamic volumes, $(P=$ .037) (Table 3). No such sex differences existed among lean individuals. Furthermore, lean and obese males and lean and obese females also did not differ in hypothalamic volumes.

There was a significant inverse relationship between BDNF levels and residualized hypothalamus volumes in obese girls $(r=-0.48, P=.045)$, whereas none existed in obese boys $(r=-0.12, P=.69)$ (Figure 3 ). We found no
TABLE 3: Hypothalamic volumes divided by group and sex.

\begin{tabular}{lccc}
\hline & Male & Female & $P$ value \\
\hline Lean & $(n=11)$ & $(n=18)$ & \\
Hypothalamus (cc) & $1.50 \pm 0.04$ & $1.44 \pm 0.03$ & .81 \\
Intracranial vault (cc) & $1316.5 \pm 101.9$ & $1142.6 \pm 97.7$ & \\
Obese & $(n=23)$ & $(n=39)$ & \\
Hypothalamus (cc) & $1.60 \pm 0.04$ & $1.48 \pm 0.03$ & .043 \\
Intracranial vault $(\mathrm{cc})$ & $1263.1 \pm 141.0$ & $1147.3 \pm 105.8$ & \\
\hline
\end{tabular}

Data are presented as absolute volumetric mean \pm SD. Comparisons were performed on intracranial vault-residualized volumes to yield the results in the table. Please note that there were significant ICV differences between males and females in general as well as for each weight group separately. Four subjects (1 lean female, 1 obese male, and 2 obese females) did not have MRI data.

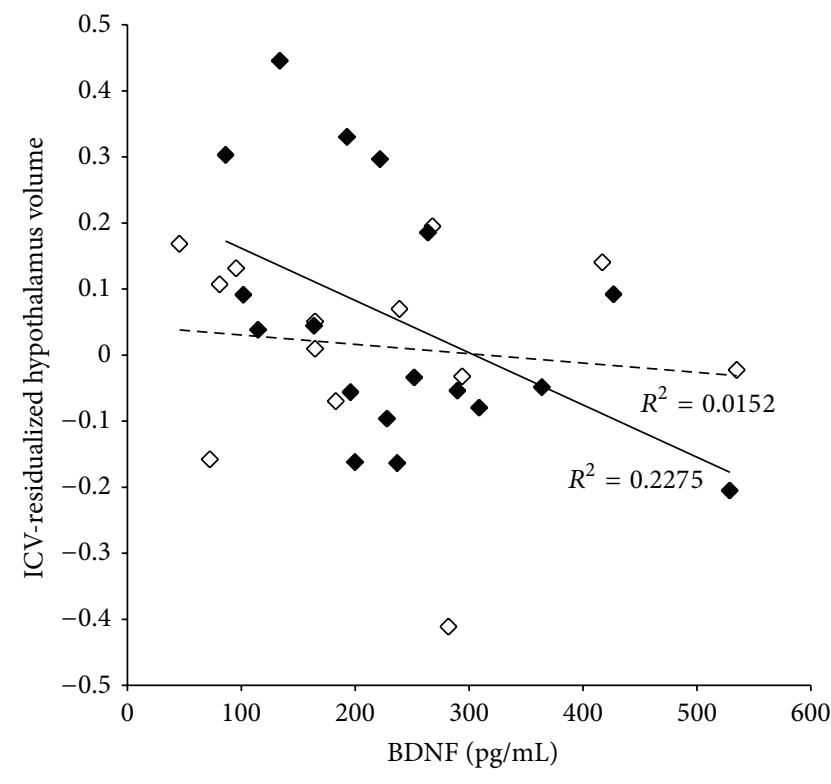

- Obese female

$-\diamond-$ Obese male

FIGURE 3: Relationship between BDNF concentration and hypothalamic volume in obese subjects. Plasma BDNF was measured by ELISA using a multiplex plate. Hypothalamic volumes were residualized to ICV volumes to account for individual head-size variability ( $n=18$ females and 13 males). Obese females and obese males are represented by closed and open diamonds, respectively.

association between hypothalamic or third ventricle volumes with either of our two markers of low-grade inflammation, CRP, and fibrinogen, or NGF (data not shown).

3.4. Sex and Significant Insulin Resistance Contribute to Hypothalamic Volume. A factorial ANOVA, performed on the whole dataset, revealed a significant interaction between the effects of sex and insulin resistance on residualized hypothalamic volume, $(F(1,87)=11.92, P=.001)$ (Figure 4$)$. Simple effect analysis showed that there were significant hypothalamus volume differences in the group with insulin resistance ( $n=23$ females and 16 males; $P=.001$ ), but there was 


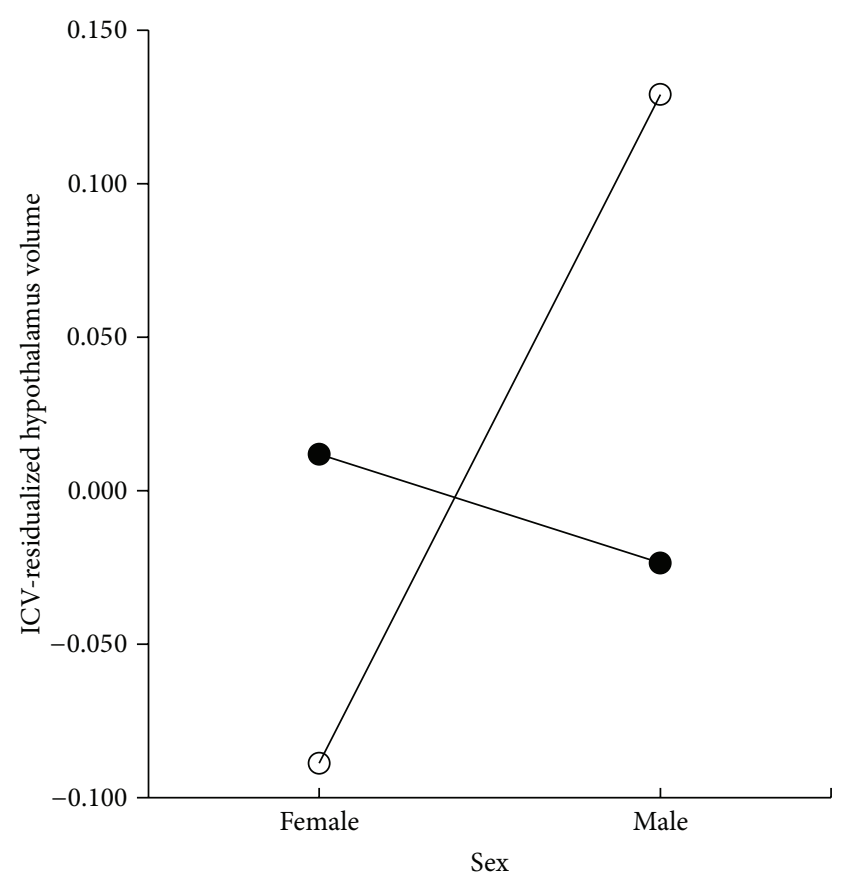

Metabolic group

$\rightarrow$ Lean control

- IR/T2DM

FIGURE 4: Interaction between sex and insulin resistance on hypothalamic volume. "Lean Control" ( $n=34$ females and 18 males), represented by closed circles, are lean adolescents without evidence of tissue insulin resistance. "IR/T2DM" $(n=23$ females and 16 males), represented by open circles, are obese adolescents with either marked insulin-resistance but not diabetes and/or obese adolescents with type 2 diabetes mellitus.

no sex difference in the lean controls $(n=34$ females and 18 males; $P=.19$ ). There was no interaction between the effects of sex and BMI on hypothalamic volume $(P=.15)$ in the insulin-resistant group when a factorial ANOVA was performed. These interactions and results persisted when $\mathrm{BMI}$ and HOMA were used as continuous variables.

\section{Discussion}

To our knowledge, this is the first report of volumetric differences in the hypothalamus between obese male and female youth. Overall, obese participants had descriptively smaller hypothalamic volumes, although they did not differ statistically. However, when divided further by sex, obese females had significantly smaller ICV-adjusted hypothalamic volume than obese males. Moreover, this sex effect is driven by metabolic dysregulation (those with type 2 diabetes or insulin resistance short of diabetes having the smallest volumes) and is associated with circulating BDNF concentrations.

Measuring the volume of the hypothalamus in vivo presents significant challenges. Unlike the hippocampus, the hypothalamus is not a discrete structure but rather a group of nuclei. Building on the work of other groups [48-51], we utilized a method that allowed us to very reliably measure the volume of the hypothalamus. By using a clearly operationalized anatomical approach in conjunction with unbiased automated segmentation, we were able to clearly separate out the hypothalamus from the surrounding white matter. Utilizing clearly defined anatomical boundaries, assisted by unbiased segmentation to highlight the hard-to-see white matter tracks, resulted in high interrater reliability with an ICC of 0.86 and 0.91 for the middle slice volume and total hypothalamus volume, respectively. Previous work from our lab shows that obesity and insulin resistance have detrimental effects on several regions of the brain, specifically the orbitofrontal cortex, hippocampus, frontal lobe, and amygdala $[6,18,60-62]$. Furthermore, females with type 2 diabetes have significantly smaller hippocampal volumes than agematched males with type 2 diabetes, despite the females being in overall better glucose control [18]. In addition to adverse effects on the brain, adult women, ranging from 20 70 years of age, are more susceptible to metabolic syndrome and cardiovascular disease than men $[63,64]$. Furthermore, females tend to have a higher levels of inflammatory markers than males $[28,29]$, and the hypothalamus is particularly sensitive to damage caused by inflammation [25].

Less is known about the differential sex impact of obesitymediated insulin resistance on brain in the youth. Nevertheless, the evidence in adults outlined above is in keeping with our current findings that obese adolescent females with marked insulin resistance have smaller hypothalamus volumes than their obese male counterparts. The volumetric differences are likely the result of an interaction between sex and insulin resistance, as shown by the very significant interaction shown in Figure 4. Association between inflammation and hypothalamus damage has been reported in animals [65-67], and there is some preliminarily data in humans [65]. However, we and others have failed to find evidence of clear association between obesity/insulin resistance and cytokine elevations [42], so whether low-grade inflammation affects hypothalamic volumes in the youth remains to be determined. With that being said, although obesity has been clearly associated with elevations in acute-phase reactants during adolescence, we failed to find any association between high-sensitivity CRP and hypothalamic volumes.

Another possible mechanism that may contribute to the observed volumetric differences is changes in vessel integrity. It is well established that obesity has a deleterious effect on endothelial function $[68,69]$. It is possible that altered endothelial function in vessels that supply certain vulnerable brain regions could play a role in the decreased hypothalamic volumes described here.

Conditions that result in increased inflammation, such as irritable bowel disease, are often associated with increases in neurotrophic factors $[33,34]$. This increase in neurotrophins, particularly BDNF, may in part occur to protect neurons from inflammatory damage [31]. Our obese adolescents, similar to previous reports in obesity [70,71], showed increased levels of circulating CRP and fibrinogen, as well as elevations in BDNF (Figure 3). Neurotrophins are also associated with eating behavior [72-74]. Mice deficient in BDNF become hyperphagic [73], and low circulating levels of BDNF can lead 
to anorexia nervosa or trigger episodes of binge eating [74]. Obese adolescents had higher concentrations of circulating BDNF. It is possible that these increases represent a compensatory mechanism, to both protect the brain from injury and to be an attempt to decrease food consumption. Although previous studies have inconsistently associated BDNF levels with adolescent obesity, given that the adolescents in the present study were in average of 17.5 years of age, these increased BDNF levels may reflect adult-like compensatory mechanisms in response to excess weight [75]. Furthermore, our obese females displayed a strong inverse relationship between circulating BDNF levels and hypothalamic volumes. It is important to note that obese females, after adjusting for their smaller ICV sizes, did have smaller hypothalamic volumes than obese males. This suggests that there may be other mechanisms at work that the BDNF cannot compensate for. For example, females are known to have more brain abnormalities in diabetes despite being in better glucose control than their male counterparts [18], so it is possible that sex hormones, which are known to have direct effects on obesity and adipose tissue [76], may also partly mediate these sex differences.

Although this study has numerous strengths, such as our high interrater reliability, the study is not without its limitations. We utilized a cross-sectional design which does not allow us to determine if obesity is the cause or result of smaller hypothalamic volume in obese females compared to obese males. Given that this is an in vivo human study, we measured circulating neurotrophins instead of measuring the localized brain neurotrophins. Thyroxin, thyroid stimulating hormone [77-79], and gonadotropin levels [80, 81], which may be dysregulated by obesity and insulin resistance, were not assessed in this study and should be evaluated in followup studies.

Future efforts should try to identify which hypothalamic nuclei may be compromised in obese youth with insulin resistance and whether with meaningful weight loss, which has been shown to partially reverse hypothalamic dysfunction [26], and reversal of insulin resistance, these volume changes are reversed and whether the tissue recovery is associated with reductions in the hypothesized compensatory BDNF elevations.

\section{Abbreviations}

$\begin{array}{ll}\text { AC: } & \text { Anterior commissure } \\ \text { BDNF: } & \text { Brain-derived neurotrophic factor } \\ \text { BMI: } & \text { Body mass index } \\ \text { CRP: } & \text { C-reactive protein } \\ \text { CSF: } & \text { Cerebral spinal fluid; } \\ \text { ELISA: } & \text { Enzyme-linked immunosorbent assay } \\ \text { FLAIR: } & \text { Fast fluid-attenuated inversion recovery } \\ \text { HOMA-IR: } & \text { Homeostasis model assessment of insulin } \\ & \text { resistance } \\ \text { ICC: } & \text { Interclass correlation coefficients } \\ \text { ICV: } & \text { Intracranial vault } \\ \text { IR: } & \text { Insulin resistance; } \\ \text { LDL: } & \text { Low-density lipoprotein } \\ \text { LHA: } & \text { Lateral hypothalamic area }\end{array}$

MIDAS: Multimodal image data analysis system

MPRAGE: Magnetization-prepared rapid acquisition gradient echo

MRI: $\quad$ Magnetic resonance imaging

NGF: $\quad$ Nerve growth factor

PC: $\quad$ Posterior commissure

ROI: Region of interest

SPM: $\quad$ Statistical Parametric mapping

VMH: Ventromedial hypothalamus.

\section{Authors' Contribution}

Jenny Ha and Jessica I. Cohen have contributed equally to this paper and should be considered co-first authors.

\section{Conflict of Interests}

None of the authors have any financial or conflicting interests to disclose.

\section{Acknowledgments}

This study was supported by a Grant from the National Institutes of Health DK 083537 (Antonio Convit) and T32DA 007254-16 (Jessica I. Cohen) and supported in part by Grant 1UL1RR029893 from the National Center for Research Resources.

\section{References}

[1] C. L. Ogden, M. D. Carroll, L. R. Curtin, M. M. Lamb, and K. M. Flegal, "Prevalence of high body mass index in US children and adolescents, 2007-2008," The Journal of the American Medical Association, vol. 303, no. 3, pp. 242-249, 2010.

[2] J. Wardle, N. H. Brodersen, T. J. Cole, M. J. Jarvis, and D. R. Boniface, "Development of adiposity in adolescence: five year longitudinal study of an ethnically and socioeconomically diverse sample of young people in Britain," The British Medical Journal, vol. 332, no. 7550, pp. 1130-1132, 2006.

[3] X. Pi-Sunyer, "The medical risks of obesity," Postgraduate Medicine, vol. 121, no. 6, pp. 21-33, 2009.

[4] D. R. Thompson, E. Obarzanek, D. L. Franko et al., "Childhood overweight and cardiovascular disease risk factors: the national heart, lung, and blood institute growth and health study," Journal of Pediatrics, vol. 150, no. 1, pp. 18-25, 2007.

[5] P. L. Yau, D. C. Javier, C. M. Ryan et al., "Preliminary evidence for brain complications in obese adolescents with type 2 diabetes mellitus," Diabetologia, vol. 53, no. 11, pp. 2298-2306, 2010.

[6] H. Bruehl, V. Sweat, A. Tirsi, B. Shah, and A. Convit, "Obese adolescents with type 2 diabetes mellitus have hippocampal and frontal lobe volume reductions," Neuroscience and Medicine, vol. 2, no. 1, pp. 34-42, 2011.

[7] P. L. Yau, M. G. Castro, A. Tagani, W. H. Tsui, and A. Convit, "Obesity and metabolic syndrome and functional and structural brain impairments in adolescence," Pediatrics, vol. 130, pp. e856-e864, 2012.

[8] A. Kalsbeek, E. Bruinstroop, C. X. Yi, L. P. Klieverik, S. E. La Fleur, and E. Fliers, "Hypothalamic control of energy metabolism via the autonomic nervous system," Annals of the New York Academy of Sciences, vol. 1212, pp. 114-129, 2010. 
[9] G. P. Chrousos, T. Kino, and E. Charmandari, "Evaluation of the hypothalamic-pituitary-adrenal axis function in childhood and adolescence," NeuroImmunoModulation, vol. 16, no. 5, pp. 272283, 2009.

[10] E. E. Benarroch, "Neural control of feeding behavior: overview and clinical correlations," Neurology, vol. 74, no. 20, pp. 16431650, 2010.

[11] R. B. S. Harris, "Role of set-point theory in regulation of body weight," FASEB Journal, vol. 4, no. 15, pp. 3310-3318, 1990.

[12] R. E. Keesey and M. D. Hirvonen, "Body weight set-points: determination and adjustment," Journal of Nutrition, vol. 127, no. 9, pp. 1875S-1883S, 1997.

[13] M. J. Müller, A. Bosy-Westphal, and S. B. Heymsfield, "Is there evidence for a set point that regulates human body weight?" F1000 Medicine Reports, vol. 2, no. 1, article 59, 2010.

[14] F. Delaere, C. Magnan, and G. Mithieux, "Hypothalamic integration of portal glucose signals and control of food intake and insulin sensitivity," Diabetes and Metabolism, vol. 36, no. 4, pp. 257-262, 2010.

[15] U. N. Das, “Obesity: genes, brain, gut, and environment," Nutrition, vol. 26, no. 5, pp. 459-473, 2010.

[16] G. J. Morton, D. E. Cummings, D. G. Baskin, G. S. Barsh, and M. W. Schwartz, "Central nervous system control of food intake and body weight," Nature, vol. 443, no. 7109, pp. 289-295, 2006.

[17] W. L. Awa, E. Fach, D. Krakow et al., "Type 2 diabetes from pediatric to geriatric age: analysis of gender and obesity among 120, 183 patients from the German/Austrian DPV database," European Journal of Endocrinology, vol. 167, no. 2, pp. 245-254, 2012.

[18] R. Hempel, R. Onopa, and A. Convit, "Type 2 diabetes affects hippocampus volume differentially in men and women," Diabetes/Metabolism Research and Reviews, vol. 28, no. 1, pp. 76-83, 2012.

[19] A. Crowley, V. Menon, D. Lessard et al., "Sex differences in survival after acute myocardial infarction in patients with diabetes mellitus (Worcester heart attack study)," The American Heart Journal, vol. 146, no. 5, pp. 824-831, 2003.

[20] A. Karamé, M. Labeeuw, P. Trolliet et al., “The impact of type 2 diabetes on mortality in end-stage renal disease patients differs between genders," Nephron-Clinical Practice, vol. 112, no. 4, pp. c268-c275, 2009.

[21] S. Natarajan, Y. Liao, D. Sinha, G. Cao, D. L. McGee, and S. R. Lipsitz, "Sex differences in the effect of diabetes duration on coronary heart disease mortality," Archives of Internal Medicine, vol. 165, no. 4, pp. 430-435, 2005.

[22] E. Barrett-Connor, E. V. Giardina, A. K. Gitt, U. Gudat, H. O. Steinberg, and D. Tschoepe, "Women and heart disease: the role of diabetes and hyperglycemia," Archives of Internal Medicine, vol. 164, no. 9, pp. 934-942, 2004.

[23] S. Cook, M. Weitzman, P. Auinger, M. Nguyen, and W. H. Dietz, "Prevalence of a metabolic syndrome phenotype in adolescents: findings from the third national health and nutrition examination survey, 1988-1994," Archives of Pediatrics and Adolescent Medicine, vol. 157, no. 8, pp. 821-827, 2003.

[24] C. E. Walden, R. H. Knopp, P. W. Wahl, K. W. Beach, and E. Strandness Jr., "Sex differences in the effect of diabetes mellitus on lipoprotein triglyceride and cholesterol concentrations," The New England Journal of Medicine, vol. 311, no. 15, pp. 953-959, 1984.

[25] E. P. Araújo, M. A. Torsoni, and L. A. Velloso, "Hypothalamic inflammation and obesity," Vitamins and Hormones, vol. 82, pp. 129-143, 2010.
[26] S. van de Sande-Lee, F. R. S. Pereira, D. E. Cintra et al., "Partial reversibility of hypothalamic dysfunction and changes in brain activity after body mass reduction in obese subjects," Diabetes, vol. 60, no. 6, pp. 1699-1704, 2011.

[27] D. Cai and T. Liu, "Hypothalamic inflammation: a double-edged sword to nutritional diseases," Annals of the New York Academy of Sciences, vol. 1243, pp. E1-E39, 2011.

[28] V. Sweat, V. Starr, H. Bruehl et al., "C-reactive protein is linked to lower cognitive performance in overweight and obese women," Inflammation, vol. 31, no. 3, pp. 198-207, 2008.

[29] J. Ren and R. O. Kelley, "Cardiac health in women with metabolic syndrome: clinical aspects and pathophysiology," Obesity, vol. 17, no. 6, pp. 1114-1123, 2009.

[30] V. Vachharajani and D. N. Granger, "Adipose tissue: a motor for the inflammation associated with obesity," IUBMB Life, vol. 61, no. 4, pp. 424-430, 2009.

[31] R. Tabakman, S. Lecht, S. Sephanova, H. Arien-Zakay, and P. Lazarovici, "Interactions between the cells of the immune and nervous system: neurotrophins as neuroprotection mediators in CNS injury," Progress in Brain Research, vol. 146, pp. 387-401, 2004.

[32] E. E. Noble, C. J. Billington, C. M. Kotz, and C. Wang, "The lighter side of BDNF", The American Journal of PhysiologyRegulatory Integrative and Comparative Physiology, vol. 300, no. 5, pp. R1053-R1069, 2011.

[33] M. Johansson, O. Norrgård, and S. Forsgren, "Are neurotrophins important in ulcerative colitis?" Annals of the New York Academy of Sciences, vol. 1107, pp. 290-299, 2007.

[34] F. F. di Mola, H. Friess, Z. W. Zhu et al., "Nerve growth factor and Trk high affinity receptor (TrkA) gene expression in inflammatory bowel disease," Gut, vol. 46, no. 5, pp. 670-679, 2000.

[35] D. Cai, J. M. Holm, I. J. Duignan et al., "BDNF-mediated enhancement of inflammation and injury in the aging heart," Physiological Genomics, vol. 24, no. 3, pp. 191-197, 2006.

[36] A. H. El-Gharbawy, D. C. Adler-Wailes, M. C. Mirch et al., "Serum brain-derived neurotrophic factor concentrations in lean and overweight children and adolescents," Journal of Clinical Endocrinology and Metabolism, vol. 91, no. 9, pp. 35483552, 2006.

[37] C. L. Roth, C. Elfers, U. Gebhardt, H. L. Muller, and T. Reinehr, "Brain-derived neurotrophic factor and its relation to leptin in obese children before and after weight loss," Metabolism, vol. 62, no. 2, pp. 226-234, 2013.

[38] M. Lommatzsch, D. Zingler, K. Schuhbaeck et al., "The impact of age, weight and gender on BDNF levels in human platelets and plasma," Neurobiology of Aging, vol. 26, no. 1, pp. 115-123, 2005.

[39] M. Suwa, H. Kishimoto, Y. Nofuji et al., "Serum brain-derived neurotrophic factor level is increased and associated with obesity in newly diagnosed female patients with type 2 diabetes mellitus," Metabolism, vol. 55, no. 7, pp. 852-857, 2006.

[40] M. Bulló, M. R. Peeraully, P. Trayhurn, J. Folch, and J. SalasSalvadó, "Circulating nerve growth factor levels in relation to obesity and the metabolic syndrome in women," European Journal of Endocrinology, vol. 157, no. 3, pp. 303-310, 2007.

[41] A. Arentoft, V. Sweat, V. Starr et al., "Plasma BDNF is reduced among middle-aged and elderly women with impaired insulin function: evidence of a compensatory mechanism," Brain and Cognition, vol. 71, no. 2, pp. 147-152, 2009. 
[42] J. I. Cohen, L. Maayan, and A. Convit, "Preliminary evidence for obesity-associated insulin resistance in adolescents without elevations of inflammatory cytokines," Diabetology and Metabolic Syndrome, vol. 4, article 26, 2012.

[43] J. Choi, L. Joseph, and L. Pilote, "Obesity and C-reactive protein in various populations: a systematic review and meta-analysis," Obesity Reviews, vol. 14, no. 3, pp. 232-244, 2013.

[44] G. C. Brooks, M. J. Blaha, and R. S. Blumenthal, "Relation of Creactive protein to abdominal adiposity," The American Journal of Cardiology, vol. 106, no. 1, pp. 56-61, 2010.

[45] H. H. Ditschuneit, M. Flechtner-Mors, and G. Adler, "Fibrinogen in obesity before and after weight reduction," Obesity Research, vol. 3, no. 1, pp. 43-48, 1995.

[46] I. Lemieux, A. Pascot, D. Prud'homme et al., "Elevated C-reactive protein: another component of the atherothrombotic profile of abdominal obesity," Arteriosclerosis, Thrombosis, and Vascular Biology, vol. 21, no. 6, pp. 961-967, 2001.

[47] F. Karege, M. Schwald, and M. Cisse, "Postnatal developmental profile of brain-derived neurotrophic factor in rat brain and platelets," Neuroscience Letters, vol. 328, no. 3, pp. 261-264, 2002.

[48] N. Loskutova, R. A. Honea, W. M. Brooks, and J. M. Burns, "Reduced limbic and hypothalamic volumes correlate with bone density in early Alzheimer's disease," Journal of Alzheimer's Disease, vol. 20, no. 1, pp. 313-322, 2010.

[49] H. E. H. Pol, P. T. Cohen-Kettenis, N. E. M. van Haren et al., "Changing your sex changes your brain: influences of testosterone and estrogen on adult human brain structure," European Journal of Endocrinology, vol. 155, no. 1, pp. S107-S114, 2006.

[50] V. Bouilleret, R. E. Hogan, D. Velakoulis et al., "Morphometric abnormalities and hyperanxiety in genetically epileptic rats: a model of psychiatric comorbidity?" NeuroImage, vol. 45 , no. 2 , pp. 267-274, 2009.

[51] A. Klomp, P. C. M. P. Koolschijn, H. E. H. Pol, R. S. Kahn, and N. E. M. van Haren, "Hypothalamus and pituitary volume in schizophrenia: a structural MRI study," International Journal of Neuropsychopharmacology, vol. 15, no. 2, pp. 281-288, 2012.

[52] J. M. Goldstein, L. J. Seidman, N. Makris et al., "Hypothalamic abnormalities in schizophrenia: sex effects and genetic vulnerability," Biological Psychiatry, vol. 61, no. 8, pp. 935-945, 2007.

[53] A. B. Hollingshead, Four Factor Index of Social Status, Yale University, Department of Sociology, New Haven, Conn, USA, 1975.

[54] M. Keskin, S. Kurtoglu, M. Kendirci, M. E. Atabek, and C. Yazici, "Homeostasis model assessment is more reliable than the fasting glucose/insulin ratio and quantitative insulin sensitivity check index for assessing insulin resistance among obese children and adolescents," Pediatrics, vol. 115, no. 4, pp. e500e503, 2005.

[55] H. Wahrenberg, K. Hertel, B. Leijonhufvud, L. Persson, E. Toft, and P. Arner, "Use of waist circumference to predict insulin resistance: retrospective study," The British Medical Journal, vol. 330, no. 7504, pp. 1363-1364, 2005.

[56] M. Turchiano, V. Sweat, A. Fierman, and A. Convit, "Obesity, metabolic syndrome, and insulin resistance in urban high school students of minority race/ethnicity," Archives of Pediatrics and Adolescent Medicine, vol. 166, no. 11, pp. 1030-1036, 2012.

[57] S. M. Gold, I. Dziobek, V. Sweat et al., "Hippocampal damage and memory impairments as possible early brain complications of type 2 diabetes," Diabetologia, vol. 50, no. 4, pp. 711-719, 2007.
[58] M. Baroncini, P. Jissendi, E. Balland et al., "MRI atlas of the human hypothalamus," NeuroImage, vol. 59, no. 1, pp. 168-180, 2012.

[59] O. Piguet, Å. Petersén, B. Y. K. Lam et al., "Eating and hypothalamus changes in behavioral-variant frontotemporal dementia," Annals of Neurology, vol. 69, no. 2, pp. 312-319, 2011.

[60] F. Cazettes, J. I. Cohen, P. L. Yau, H. Talbot, and A. Convit, "Obesity-mediated inflammation may damage the brain circuit that regulates food intake," Brain Research, vol. 1373, pp. 101-109, 2011.

[61] J. I. Cohen, K. F. Yates, M. Duong, and A. Convit, "Obesity, orbitofrontal structure and function are associated with food choice: a cross-sectional study," BMJ Open, vol. 1, no. 2, Article ID e000175, 2011.

[62] L. Maayan, C. Hoogendoorn, V. Sweat, and A. Convit, "Disinhibited eating in obese adolescents is associated with orbitofrontal volume reductions and executive dysfunction," Obesity, vol. 19, no. 7, pp. 1382-1387, 2011.

[63] V. Regitz-Zagrosek, E. Lehmkuhl, and S. Mahmoodzadeh, "Gender aspects of the role of the metabolic syndrome as a risk factor for cardiovascular disease," Gender Medicine, vol. 4, supplement 2, pp. S162-S177, 2007.

[64] R. M. Mabry, M. M. Reeves, E. G. Eakin, and N. Owen, "Gender differences in prevalence of the metabolic syndrome in gulf cooperation council countries: a systematic review," Diabetic Medicine, vol. 27, no. 5, pp. 593-597, 2010.

[65] J. P. Thaler, C. Yi, E. A. Schur et al., "Obesity is associated with hypothalamic injury in rodents and humans," Journal of Clinical Investigation, vol. 122, no. 1, pp. 153-162, 2012.

[66] C. T. de Souza, E. P. Araujo, S. Bordin et al., "Consumption of a fat-rich diet activates a proinflammatory response and induces insulin resistance in the hypothalamus," Endocrinology, vol. 146, no. 10, pp. 4192-4199, 2005.

[67] K. A. Posey, D. J. Clegg, R. L. Printz et al., "Hypothalamic proinflammatory lipid accumulation, inflammation, and insulin resistance in rats fed a high-fat diet," The American Journal of Physiology-Endocrinology and Metabolism, vol. 296, no. 5, pp. E1003-E1012, 2009.

[68] R. M. Cubbon, M. B. Kahn, and S. B. Wheatcroft, "Effects of insulin resistance on endothelial progenitor cells and vascular repair," Clinical Science, vol. 117, no. 5, pp. 173-190, 2009.

[69] S. M. P. Kerr, M. B. E. Livingstone, T. A. McCrorie, and J. M. W. Wallace, "Endothelial dysfunction associated with obesity and the effect of weight loss interventions," Proceedings of the Nutrition Society, vol. 70, no. 4, pp. 418-425, 2011.

[70] A. D. Pradhan, J. E. Manson, N. Rifai, J. E. Buring, and P. M. Ridker, "C-reactive protein, interleukin 6, and risk of developing type 2 diabetes mellitus," The Journal of the American Medical Association, vol. 286, no. 3, pp. 327-334, 2001.

[71] P. M. Ridker, J. E. Buring, N. R. Cook, and N. Rifai, "Creactive protein, the metabolic syndrome, and risk of incident cardiovascular events: an 8-year follow-up of 14719 initially healthy American women," Circulation, vol. 107, no. 3, pp. 391397, 2003.

[72] B. Lebrun, B. Bariohay, E. Moyse, and A. Jean, "Brain-derived neurotrophic factor (BDNF) and food intake regulation: a minireview," Autonomic Neuroscience: Basic and Clinical, vol. 126-127, pp. 30-38, 2006.

[73] J. Cordeira and M. Rios, "Weighing in the role of BDNF in the central control of eating behavior," Molecular Neurobiology, vol. 44, pp. 441-448, 2011. 
[74] H. Rosas-Vargas, J. D. Martínez-Ezquerro, and T. Bienvenu, "Brain-derived neurotrophic factor, food intake regulation, and obesity," Archives of Medical Research, vol. 42, no. 6, pp. 482494, 2011.

[75] C. L. Ooi, J. L. Kennedy, and R. D. Levitan, "A putative model of overeating and obesity based on brain-derived neurotrophic factor: direct and indirect effects," Behavioral Neuroscience, vol. 126, no. 4, pp. 505-514, 2012.

[76] J. S. Mayes and G. H. Watson, "Direct effects of sex steroid hormones on adipose tissues and obesity," Obesity Reviews, vol. 5, no. 4, pp. 197-216, 2004.

[77] M. Bastemir, F. Akin, E. Alkis, and B. Kaptanoglu, "Obesity is associated with increased serum TSH level, independent of thyroid function," Swiss Medical Weekly, vol. 137, no. 29-30, pp. 431-434, 2007.

[78] C. Brufani, M. Manco, V. Nobili, D. Fintini, F. Barbetti, and M. Cappa, "Thyroid function tests in obese prepubertal children: correlations with insulin sensitivity and body fat distribution," Hormone Research in Paediatrics, vol. 78, pp. 100-105, 2012.

[79] T. Farasat, A. M. Cheema, and M. N. Khan, "Hyperinsulinemia and insulin resistance is associated with low $\mathrm{T}(3) / \mathrm{T}(4)$ ratio in pre diabetic euthyroid Pakistani subjects," Journal of Diabetes and Its Complications, vol. 26, no. 6, pp. 522-525, 2012.

[80] K. Michalakis, G. Mintziori, A. Kaprara, B. C. Tarlatzis, and D. G. Goulis, "The complex interaction between obesity, metabolic syndrome and reproductive axis: a narrative review," Metabolism, vol. 62, no. 4, pp. 457-478, 2013.

[81] A. B. Motta, "The role of obesity in the development of polycystic ovary syndrome," Current Pharmaceutical Design, vol. 18, no. 17, pp. 2482-2491, 2012. 


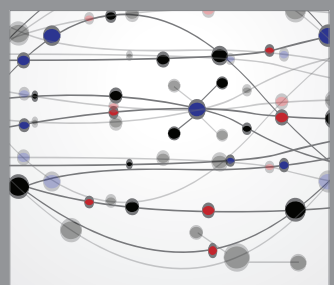

The Scientific World Journal
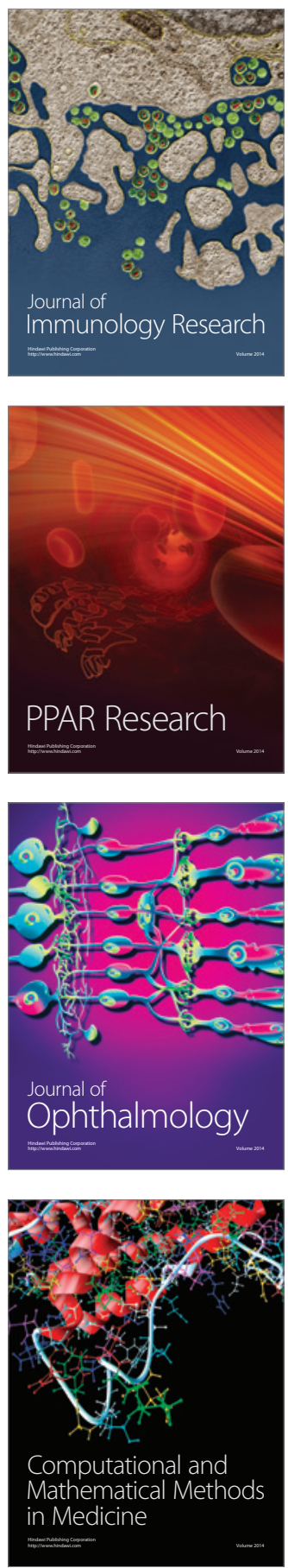

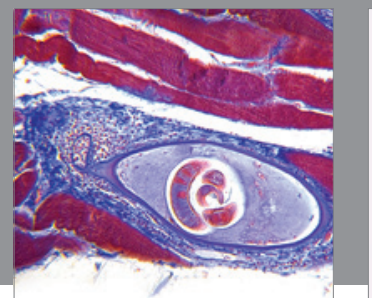

Gastroenterology

Research and Practice
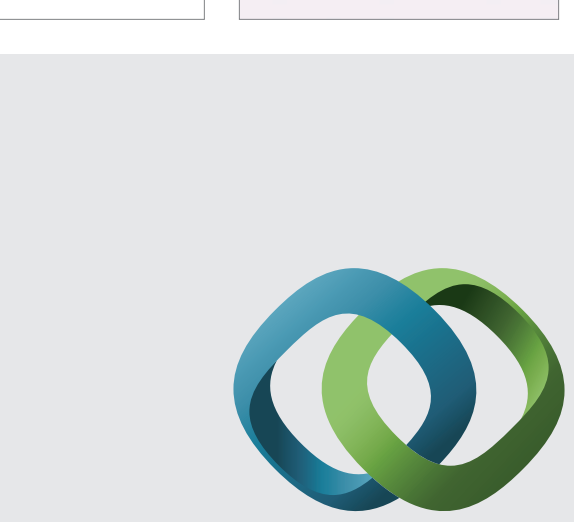

\section{Hindawi}

Submit your manuscripts at

http://www.hindawi.com
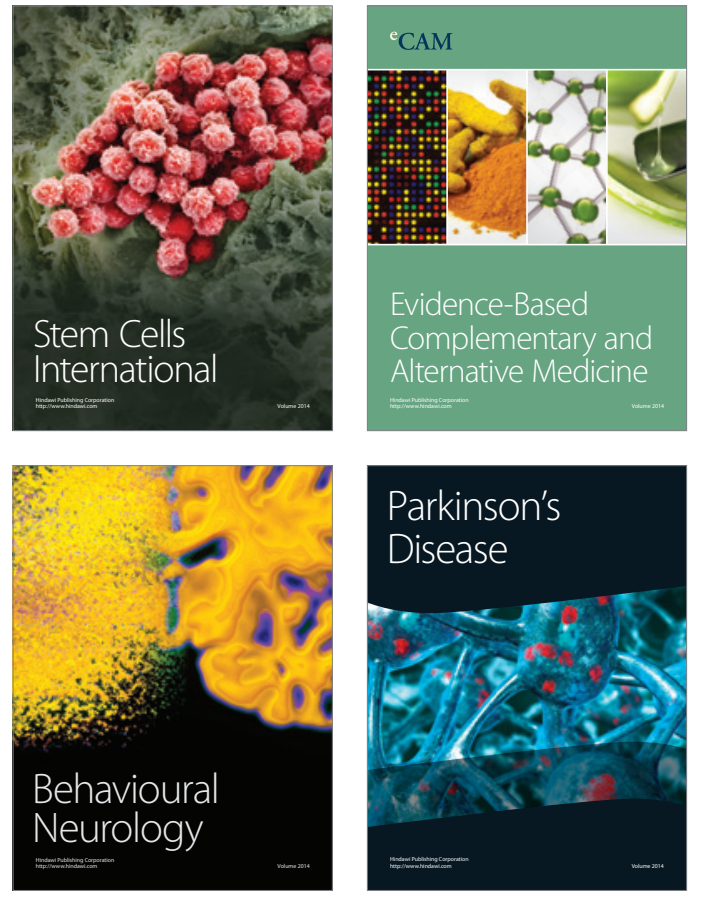
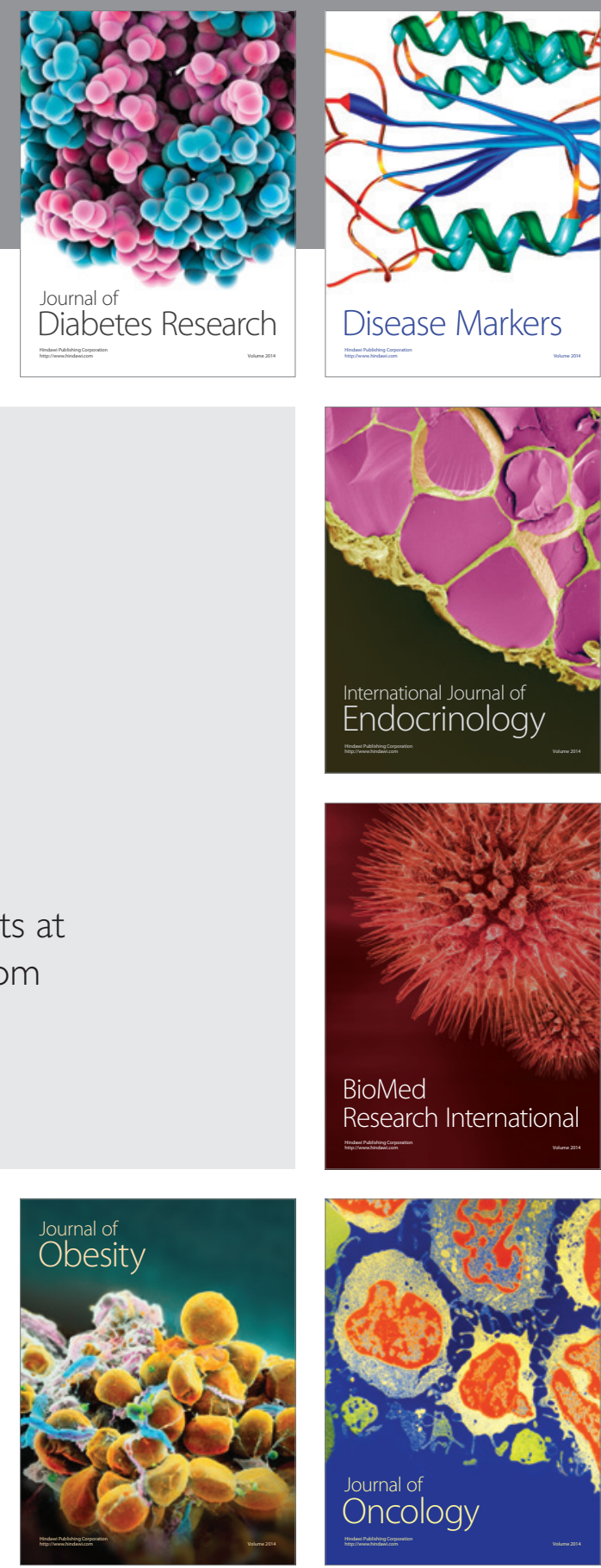

Disease Markers
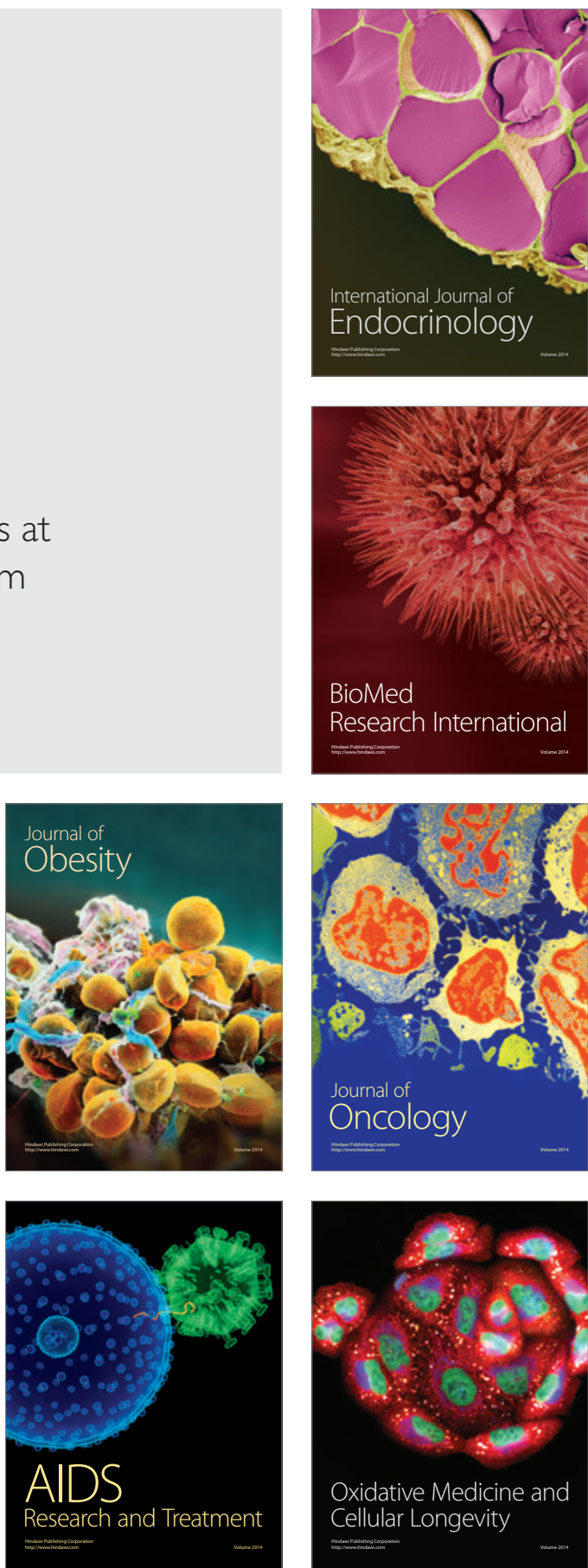